\title{
Structural Characterization of Boro-Titanized AISI 1040 Steel
}

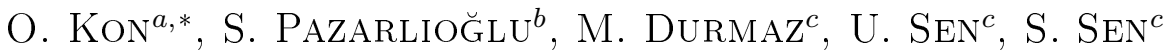 \\ ${ }^{a}$ Sakarya University, Technical Education Faculty, Metal Education Department, 54187, Serdivan Sakarya, Turkey \\ ${ }^{b}$ Marmara University, Technical Education Faculty, Metal Education Department, 34722, Istanbul Turkey \\ ${ }^{c}$ Sakarya University, Engineering Faculty, Department of Metallurgy and Materials Engineering, \\ 54187, Sakarya, Turkey
}

\begin{abstract}
In this study, boro-titanizing treatment was applied to AISI 1040 steel. In the coating treatment, steel samples were pre-boronized in a slurry salt bath consisting of borax, boric acid and ferro-silicon at $900{ }^{\circ} \mathrm{C} \mathrm{for} 2 \mathrm{~h}$, then titanized by thermo-reactive deposition technique (TRD) in a powder mixture consisting of ferro-titanium, ammonium chloride, alumina and naphthalene at $1000^{\circ} \mathrm{C}$ for $1-4 \mathrm{~h}$. The coated samples were characterized by $\mathrm{X}-$ ray diffraction analysis (XRD), scanning electron microscope (SEM), glow discharge optical emission spectroscopy (GDOES) and micro-hardness tests. Coated layer formed on the pre-boronized AISI 1040 steel was compact and homogeneous. X-ray studies showed that the phases formed on the steel surfaces are $\mathrm{TiB}_{2}, \mathrm{TiC}, \mathrm{TiN}$ and $\mathrm{Fe}_{2} \mathrm{~B}$. The depth of the coating layer ranged from $3.41 \pm 0.47 \mu \mathrm{m}$ to $6.59 \pm 0.51 \mu \mathrm{m}$, depending on treatment time. A higher treatment time resulted in a thicker boro-titanized layer. The average hardness of the coating layer was $4527 \pm 284 \mathrm{HV}_{0.005}$
\end{abstract}

DOI: 10.12693/APhysPolA.127.1211

PACS: 81.65.Lp, 62.20.Qp

\section{Introduction}

Multi-component and multiphase thin films are of increasing interest as protective coating system, because of their excellent combination of physical, chemical, and mechanical properties. Especially, titanium based hard coatings like $\mathrm{TiN}, \mathrm{TiC}, \mathrm{TiB}_{2}$, TiCN, TiBN and $\mathrm{TiBCN}$ are famous [1-10]. It has been shown that thin films of the Ti-B-C-N system exhibits good physical and mechanical properties along with excellent wear resistance [11-13]. In general, structural, mechanical and tribological properties of Ti-B-C-N coating produced by magnetron sputtering [14-19], IBAD [20], PACVD [21-24], LPCVD [25] and PVD [24, 26] techniques were reported in the literature. Although there are a lot of studies available in the literature about coatings including $\mathrm{Ti}$, $\mathrm{B}, \mathrm{C}$ and $\mathrm{N}$ elements $[1,27]$, there is not any reported study about the deposition of Ti-B-C-N-based coatings by thermo-reactive diffusion (TRD) method. TRD process is relatively simple and requires no complex hardware, gives good bonding strength due to diffusional high temperature chemical reactions [28]. Moreover the heat treatment of the steel substrates can be realized at the end of titanizing treatment without reheating. Titanizing treatment is realized at the temperatures of $800{ }^{\circ} \mathrm{C}$ to $1100{ }^{\circ} \mathrm{C}[29]$.

In the present study, boro-titanizing treatment was performed on AISI 1040 steel substrate by a duplex treatment. The first step in the process was the boronizing treatment in order to produce iron boride phases on the substrate. Iron boride phase was intended to be used as

*corresponding author; e-mail: okon42@hotmail.com the boron source during the next step. The second step was the titanizing treatment, for production of titaniumbased compounds on the surface of the pre-boronized steel. The main goal of the study was to make the structural characterization of boro-titanized layer formed on the pre-boronized steel by TRD method.

\section{Experimental procedure}

The material used in the boro-titanizing treatment was AISI 1040 steel which consisted of $0.415 \%$ C, $0.015 \% \mathrm{Cr}$, $0.788 \%$ Mn, $0.033 \%$ Mo, $0.076 \%$ Ni, $0.137 \%$ Si, $0.024 \%$ P and $0.031 \% \mathrm{~S}$ and iron (balance). Before treatment, the samples were cut into pieces of $20 \mathrm{~mm}$ in diameter and $5 \mathrm{~mm}$ in length, and ground with emery paper of up to 1200 grid and washed ultrasonically for $15 \mathrm{~min}$ in ethyl alcohol. The boronizing treatment was carried out in a slurry salt bath consisting of borax, boric acid and ferro-silicon at $900{ }^{\circ} \mathrm{C}$ for $2 \mathrm{~h}$ in the first step of the boro-titanizing treatment. In the second step, preboronized steel samples were titanized by pack method in a powder mixture consisting of ferro-titanium, ammonium chloride, alumina and naphthalene at $1000{ }^{\circ} \mathrm{C}$ for 1-4 h. The samples were directly immersed into the powder mixture in an alumina crucible. An alumina lid was used to close the box and alumina cement was used for sealing the crucible. After the treatment, the samples were cooled in the box for $1 \mathrm{~h}$ in the air.

The boro-titanized samples were ground from crosssections and polished with $0.3 \mu \mathrm{m}$ alumina paste and then etched with $3 \%$ Nital for metallographic examinations. Nickon Epiphot-200 optical microscope with optical micrometer was used for measuring the depth of coating layer formed on the steel samples. In the scanning electron microscopy (SEM) and glow discharge optical 
emission spectroscopy (GDOES), the samples were analyzed from the cross-sections. Micro-hardness measurements were performed using Future-Tech FM-700 microhardness tester under the loads of 5 gf from the surface to the interior. X-ray diffraction (XRD) analyses were carried out on the surfaces of the coated sample with $2 \theta$ varying from $10^{\circ}$ to $120^{\circ}$, using $\mathrm{Cu} \mathrm{K}_{\alpha}$ radiation.

\section{Results and discussion}

Figure 1 shows a SEM micrograph of the AISI 1040 steel boro-titanized at $1000{ }^{\circ} \mathrm{C}$ for $2 \mathrm{~h}$. Coating layer includes three distinct regions; these are (i) a boro-titanized layer formed on the pre-boronized steel samples, (ii) an iron boride layer took place under the boro-titanized layer and (iii) the matrix. Coating layers, formed on the AISI 1040 steels, were compact and homogeneous. XRD analysis of AISI 1040 steel boro-titanized at $1000{ }^{\circ} \mathrm{C}$ for $2 \mathrm{~h}$ showed that the phases formed in the coating are $\mathrm{TiB}_{2}, \mathrm{TiC}$, TiN and $\mathrm{Fe}_{2} \mathrm{~B}$, as seen in Fig. 2. The phases formed on the pre-boronized steel by titanizing process resulted in formation of TiBCN coating which is of similar character to TiBCN coatings reported elsewhere [23, 24]. Boro-titanizing is a duplex treatment which includes boronizing and titanizing processes.

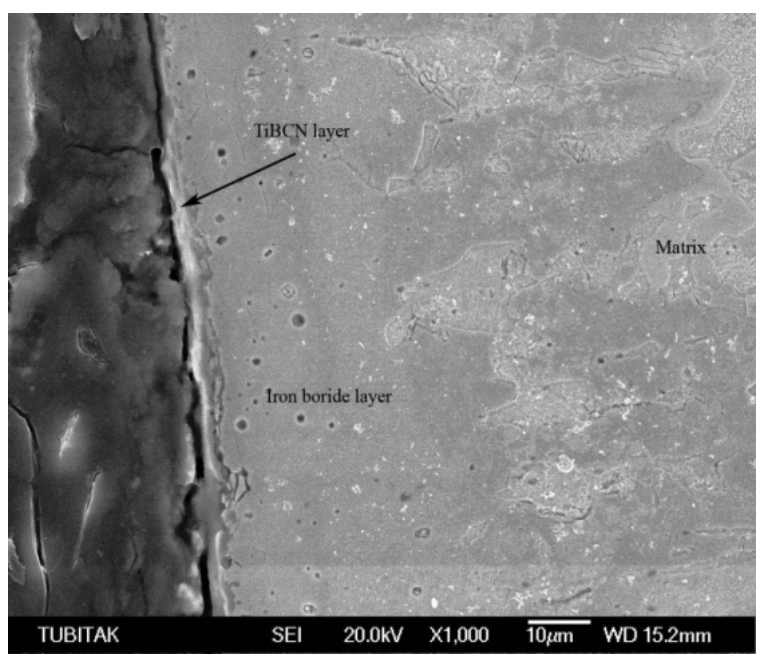

Fig. 1. SEM image of AISI 1040 steel boro-titanized at $1000^{\circ} \mathrm{C}$ for $2 \mathrm{~h}$.

GDOES analysis in Fig. 3 showed that the borotitanizing treatment increased the amount of titanium, boron, carbon and nitrogen on the steel surface, as seen in Fig. 3. As shown in Fig. 3, titanium, boron and carbon were concentrated in the boro-titanized layer. In addition, nitrogen was rich on the outer parts of the coating layer. Iron boride layer took place under the borotitanized layer (see Fig. 1 and 3 ). $\quad \mathrm{Fe}_{2} \mathrm{~B}$ phase shown on the XRD diagram is resulted from the boride layer beneath the boro-titanized steel (Fig. 2).

The depth of the boro-titanized layer ranged from $3.41 \pm 0.47 \mu \mathrm{m}$ to $6.59 \pm 0.51 \mu \mathrm{m}$, depending on the

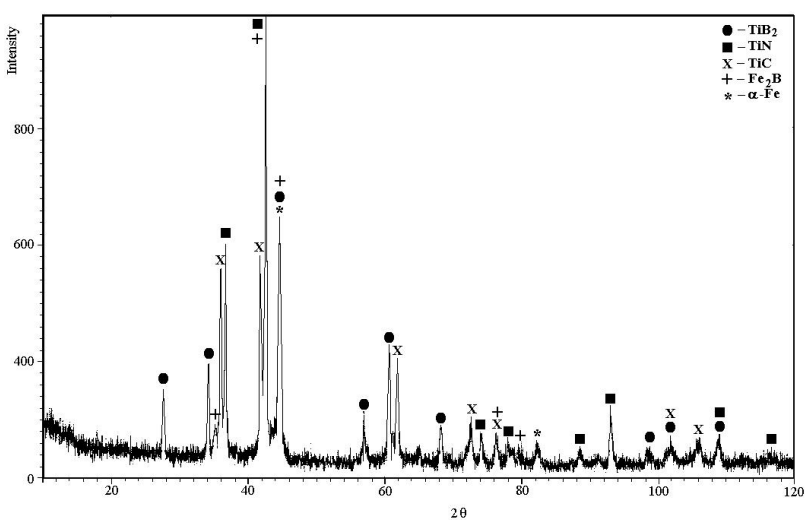

Fig. 2. X-ray diffraction patterns of AISI 1040 steel boro-titanized at $1000{ }^{\circ} \mathrm{C}$ for $2 \mathrm{~h}$.

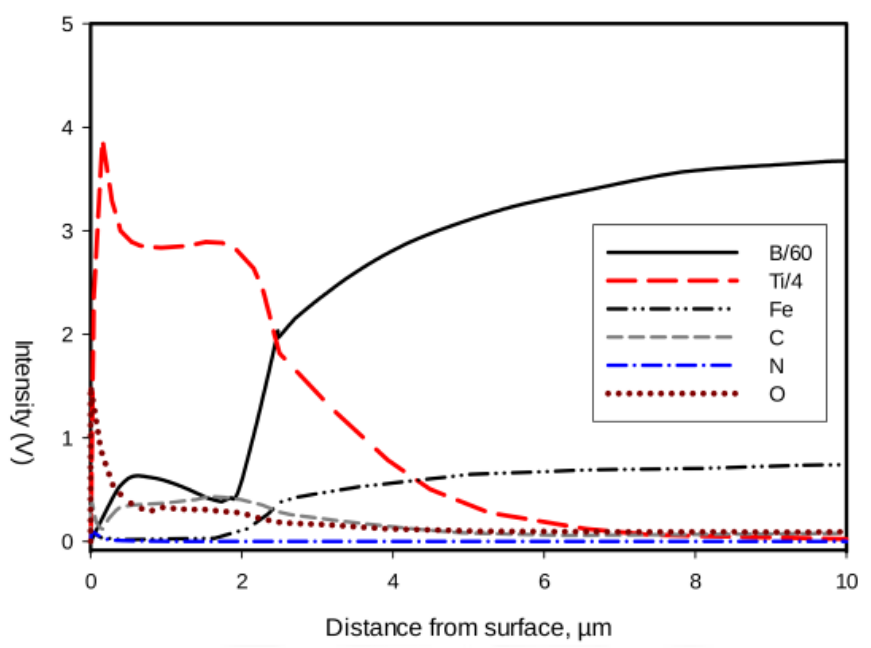

Fig. 3. GDOES analysis of boro-titanized AISI 1040 steel at $1000{ }^{\circ} \mathrm{C}$ for $2 \mathrm{~h}$ from surface to interior.

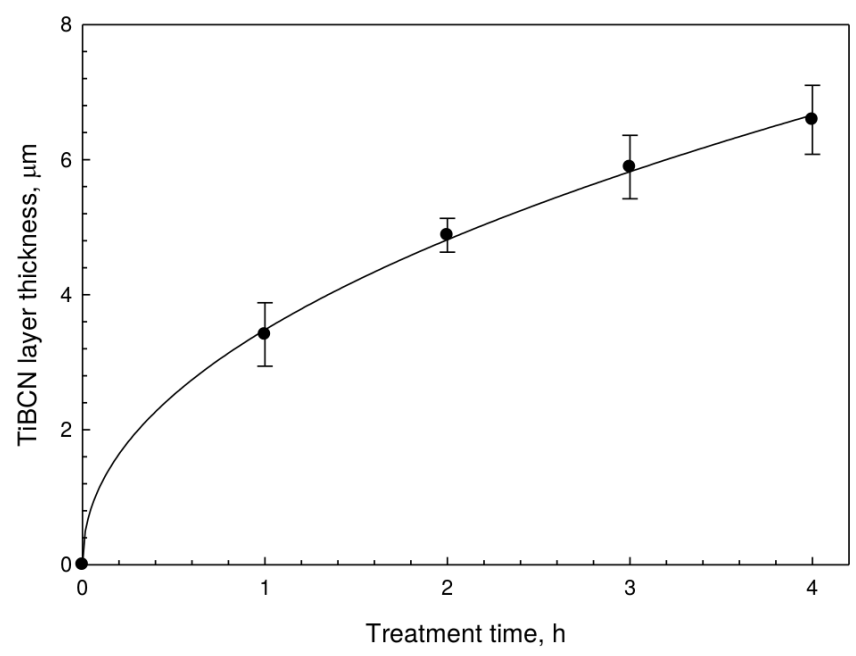

Fig. 4. Dependence of thickness of boro-titanized layer on the titanizing time. 
treatment time (see Fig. 4). The thickness of borotitanized layer increases with the titanizing time. In the thermo-chemical coating processes, the coating thickness increases with the process time and temperature. Bath composition, substrate, treatment time and temperature all affect the coating layer thickness in the thermo reactive deposition processes [25]. The average hardness of the boro-titanized layer was $4527 \pm 284 \mathrm{HV}_{0.005}$. This is in good agreement with H. Holzschuh [26]. High hardness is the consequence of the presence of hard phases $\left(\mathrm{TiB}_{2}, \mathrm{TiC}\right.$ and $\left.\mathrm{TiN}\right)$ in the boro-titanized layer, which is confirmed by XRD analysis (Fig. 2).

\section{Conclusions}

1. It has been proven that boro-titanizing treatment can be applied to AISI 1040 steel.

2. Boro-titanized layer was compact and homogeneous.

3. Coating layer includes three distinct regions; (i) boro-titanized layer, (ii) iron boride layer underneath the boro-titanized layer and (iii) the matrix.

4. Boro-titanized layer thickness changed between $3.41 \pm 0.47 \mu \mathrm{m}$ to $6.59 \pm 0.51 \mu \mathrm{m}$ depending on treatment time $(1-4 \mathrm{~h})$ at $1000^{\circ} \mathrm{C}$. Thickness of borotitanized layer increases with the titanizing time.

5 . The average hardness of boro-titanized layer was $4527 \pm 284 \mathrm{HV}_{0.005}$.

6. The phases formed on the boro-titanized AISI 1040 steel surfaces were $\mathrm{TiB}_{2}, \mathrm{TiC}, \mathrm{TiN}$ and $\mathrm{Fe}_{2} \mathrm{~B}$.

7. The phases formed on the pre-boronized steel samples by titanizing process resulted in formation of TiBCN coatings.

\section{Acknowledgments}

Financial support was provided by the DPT Project, No:2003K120970

\section{References}

[1] B. Prakash, E. Richter, H. Pattyn, J.P. Celis, Surf. Coat. Tech. 173, 150 (2003).

[2] D. Demirskyi, Y. Sakka, J. Eur. Ceram. Soc. 35, 405 (2015).

[3] R. Wuhrer, W.Y. Yeung, T. Lucey, J. Giddings, G. McCredie, Microsc. Microanal. 15, 1034 (2009).

[4] J. Lin, J.J. Moore, B. Mishra, M. Pinkas, W.D. Sprou, Acta Mater. 58, 1554 (2010).

[5] P.Ch. Tsai, W.J. Chen, J.H. Che, C.L. Chang, Thin Solid Films 517, 5044 (2009).

[6] S.M. Aouadi, M. Debessai, F. Namavar, K.C. Wong, K.A.R. Mitchell, Surf. Coat. Tech. 183, 369 (2004).

[7] A. Yazdani, M. Soltanieh, H. Aghajani, S. Rastegari, J. Nano Research 11, 79 (2010).
[8] G. Deniz, S. Sen, U. Sen, Mater. Sci. Forum 554, 219 (2007).

[9] U. Sen, Mater. Des. 26, 167 (2005).

[10] U. Sen, Vacuum 75, 339 (2004).

[11] D. Zhong, E. Sutter, J.J. Moore, G.G.W. Mustoe, E.A. Levashov, J. Disam, Thin Solid Films 398-399, 320 (2001).

[12] E.A. Levashov, V.I. Kosayanin, L.M. Krukova, J.J. Moore, D.J. Olson, Surf. Coat. Tech. 92, 34 (1997).

[13] D. Zhong, J.J Moore, B.M. Mishra, T. Ohno, E.A. Lavashov, J. Disam, Surf. Coat. Tech. 163164, 50 (2003)

[14] J.H. Hsieh, W. Wu, C. Li, C.H. Yu, B.H. Tan, Surf. Coat. Tech. 163-164, 233 (2003).

[15] M.S. Wong, Y.C. Lee, Surf. Coat. Tech. 120-121, 194 (1999).

[16] F. Kustas, B. Mishra, J. Zhou, Surf. Coat. Tech. 153, 25 (2002).

[17] P.H. Mayrhofer, C. Mitterer, Surf. Coat. Tech. 133134, 131 (2000).

[18] C. Mitterer, P.H. Mayrhofer, M. Beschliesser, P. Losbichler, P. Warbichler, F. Hofer, P.N. Gibson, W. Gissler, H. Hruby, J. Musil, J. Vicek, Surf. Coat. Tech. 120-121, 405 (1999).

[19] J. Chaleix, J. Machet, Surf. Coat. Tech. 91, 74 (1997).

[20] S.M. Aouadi, F. Namavar, T.Z. Gorishnyy, S.L. Rohde, Surf. Coat. Tech. 160, 145 (2002).

[21] K.B. Müller, J. Mater. Process. Tech. 130-131, 432 (2002).

[22] C. Pfohl, K.T. Rie, Surf. Coat. Tech. 142-144, 1116 (2001).

[23] P. Holubar, M. Jilek, M. Sima, Surf. Coat. Tech. 133-134, 145 (2000).

[24] S. Shimada, M. Takahashi, J. Tsujino, I. Yamazaki, K. Tsuda, Surf. Coat. Tech. 201, 7194 (2007).

[25] O. Ozdemir, S. Sen, U. Sen, Vacuum 81, 567 (2007).

[26] H. Holzschuh, Int. J. Refract. Met. H. 20, 143 (2002).

[27] D. Zhong, E. Mateeva, I. Dahan, J.J. Moore, G.G.W. Mustoe, T. Ohno, J. Disam, S. Thiel, Surf. Coat. Tech. 133-134, 8 (2000).

[28] I. Konyashin, Int. J. Refract. Met. H. 19, 523 (2001).

[29] H. Cao, C.P. Luo, J. Liu, G. Zou, Surf. Coat. Tech. 201, 7970 (2007). 